Supplement of Atmos. Chem. Phys., 21, 15309-15336, 2021

https://doi.org/10.5194/acp-21-15309-2021-supplement

(C) Author(s) 2021. CC BY 4.0 License.

(c) (1)

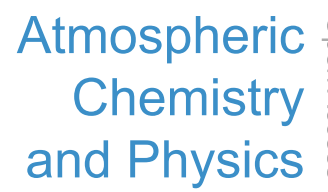

Supplement of

\title{
Three-dimensional climatology, trends, and meteorological drivers of global and regional tropospheric type-dependent aerosols: insights from 13 years (2007-2019) of CALIOP observations
}

Ke Gui et al.

Correspondence to: Huizheng Che (chehz@cma.gov.cn)

The copyright of individual parts of the supplement might differ from the article licence. 
Table S1. Classification of the 12 regions of interest (ROIs) in this study.

\begin{tabular}{ccc}
\hline Region & Abbreviation & Latitude and longitude ranges \\
\hline Eastern United States & EUS & $73^{\circ} \mathrm{W}-94^{\circ} \mathrm{W}, 29^{\circ} \mathrm{N}-45^{\circ} \mathrm{N}$ \\
Western Europe & WEU & $10^{\circ} \mathrm{W}-18^{\circ} \mathrm{E}, 37^{\circ} \mathrm{N}-59^{\circ} \mathrm{N}$ \\
Southern Asia & SA & $72^{\circ} \mathrm{E}-90^{\circ} \mathrm{E}, 10^{\circ} \mathrm{N}-30^{\circ} \mathrm{N}$ \\
Northern China & NC & $108^{\circ} \mathrm{E}-120^{\circ} \mathrm{E}, 30^{\circ} \mathrm{N}-40^{\circ} \mathrm{N}$ \\
Southern China & SC & $108^{\circ} \mathrm{E}-120^{\circ} \mathrm{E}, 20^{\circ} \mathrm{N}-30^{\circ} \mathrm{N}$ \\
Northeastern Asia & NEA & $125^{\circ} \mathrm{E}-145^{\circ} \mathrm{E}, 30^{\circ} \mathrm{N}-41^{\circ} \mathrm{N}$ \\
Sahara Desert & SD & $17^{\circ} \mathrm{W}-20^{\circ} \mathrm{E}, 3^{\circ} \mathrm{N}-25^{\circ} \mathrm{N}$ \\
Middle East & ME & $38^{\circ} \mathrm{E}-56^{\circ} \mathrm{E}, 14^{\circ} \mathrm{N}-33^{\circ} \mathrm{N}$ \\
Northwestern China & NWC & $73^{\circ} \mathrm{E}-94^{\circ} \mathrm{E}, 35^{\circ} \mathrm{N}-47^{\circ} \mathrm{N}$ \\
Amazon Zone & AMZ & $46^{\circ} \mathrm{W}-60^{\circ} \mathrm{W}, 1^{\circ} \mathrm{S}-22^{\circ} \mathrm{S}$ \\
Central Southern Africa & $\mathrm{CSA}$ & $12^{\circ} \mathrm{E}-33^{\circ} \mathrm{E}, 2^{\circ} \mathrm{S}-18^{\circ} \mathrm{S}$ \\
Southeastern Asia & SEA & $96^{\circ} \mathrm{E}-127^{\circ} \mathrm{E}, 8^{\circ} \mathrm{S}-18^{\circ} \mathrm{N}$ \\
\hline
\end{tabular}



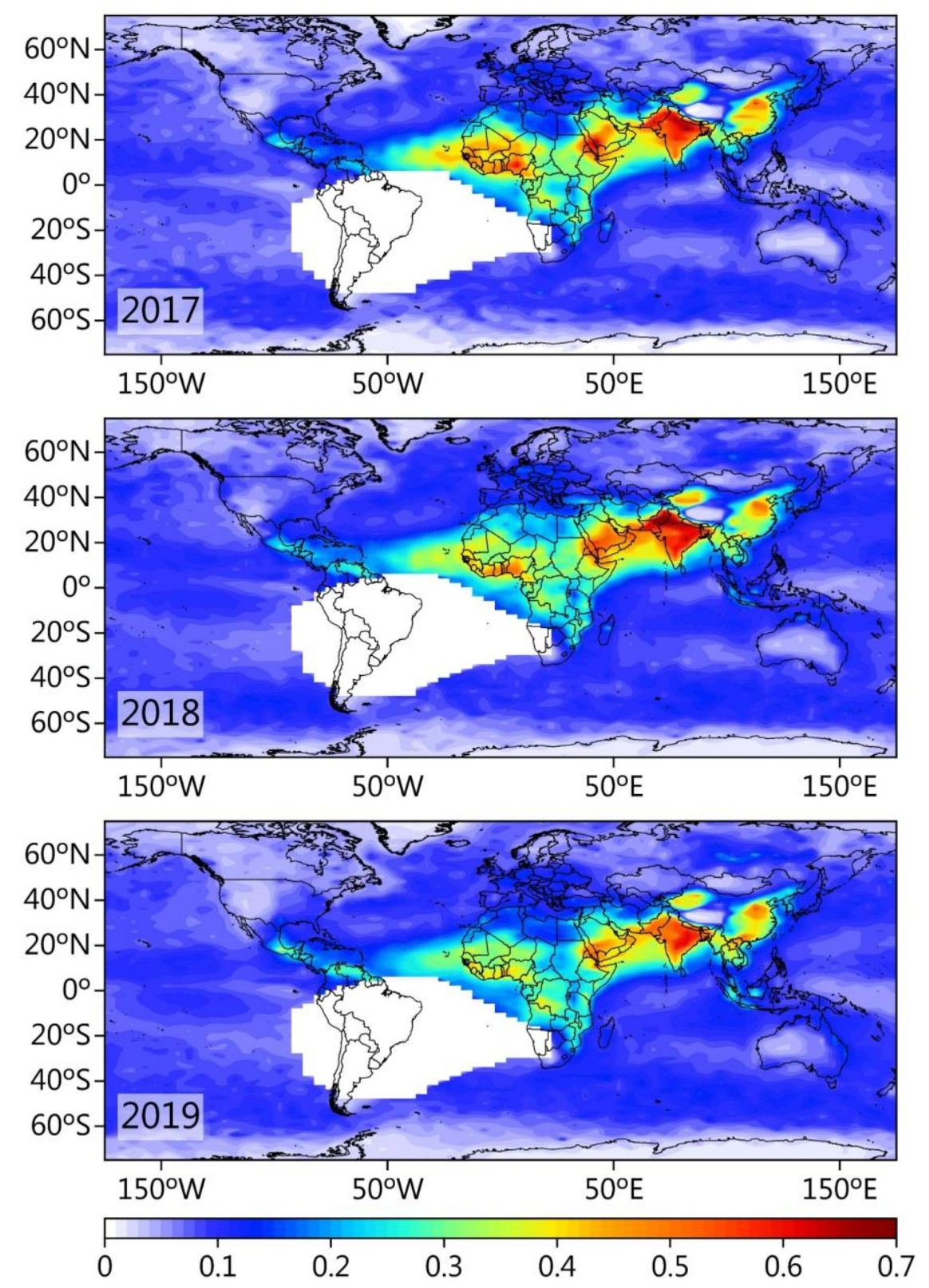

Figure S1. Areas within and near the South Atlantic anomaly region that have been excluded from this study due to an elevated frequency of low energy laser shots encountered by CALIOP since September 2016. The shading shows the annual distribution of 35 TAOD for each year from 2017-2019, with the white areas corresponding to the South Atlantic anomaly areas encountered by CALIOP each year. 
(a) TAEC

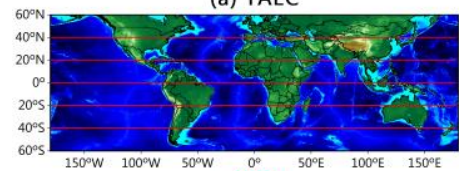

\begin{tabular}{ccccccc}
$150^{\circ} \mathrm{W}$ & $100^{\circ} \mathrm{W} \quad 50^{\circ} \mathrm{W}$ & $0^{\circ}$ & $50^{\circ} \mathrm{E}$ & $100^{\circ} \mathrm{E}$ & $150^{\circ} \mathrm{E}$ \\
\hline & & $40^{\circ} \mathrm{N}$ & & & \\
\hline
\end{tabular}

$150^{\circ} \mathrm{W} \quad 100^{\circ} \mathrm{W} \quad 50^{\circ} \mathrm{W} \quad 0^{\circ}$
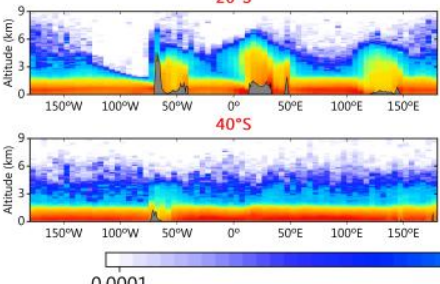
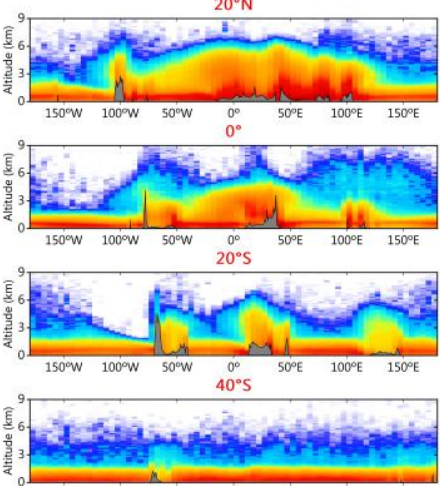

(b) DAEC

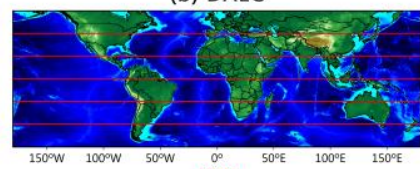

$40^{\circ} \mathrm{N}$
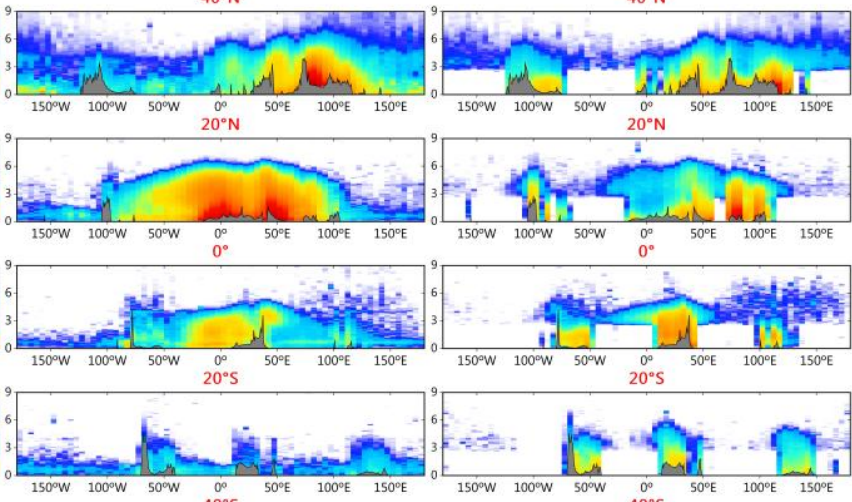

$150^{\circ} \mathrm{W} 100^{\circ} \mathrm{W} \quad 50^{\circ} \mathrm{W}$,
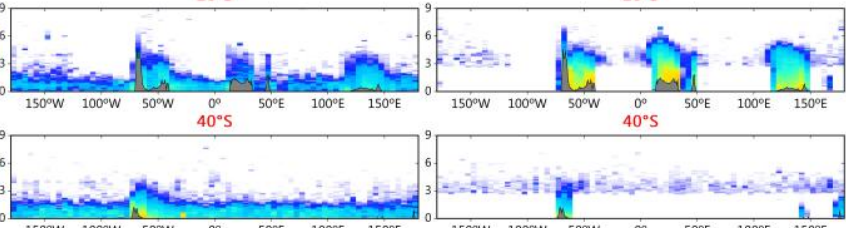

0.00

(c) PDAEC

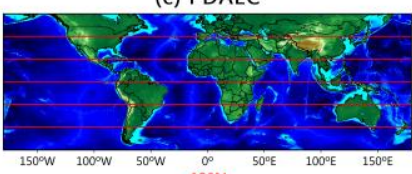

$\stackrel{\infty}{0^{\circ} \mathrm{N}}$

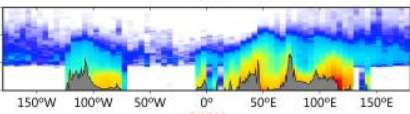

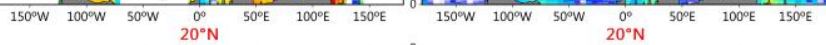
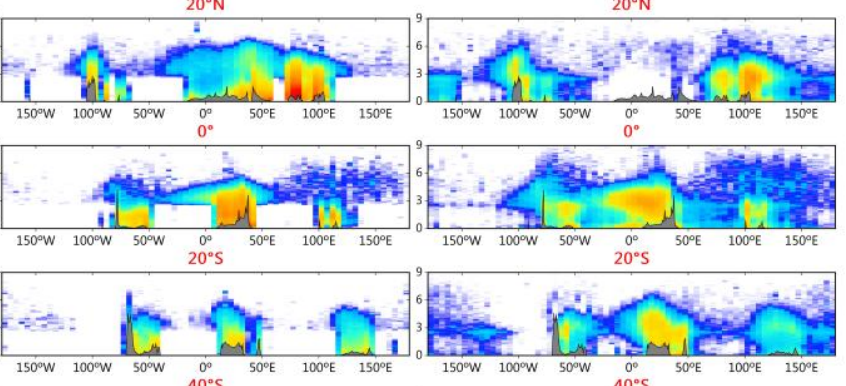

Figure S2. Zonal vertical profiles of multi-year (2007-2019) average aerosol extinction coefficients (AEC) due to type-dependent aerosols: (a) total aerosols, (b) dust, (c) polluted dust (PD), and (d) smoke. From top to bottom are $40^{\circ} \mathrm{N}, 2^{\circ} \mathrm{N}, 0^{\circ}, 20^{\circ} \mathrm{S}$, and $40^{\circ} \mathrm{S}$, respectively. 

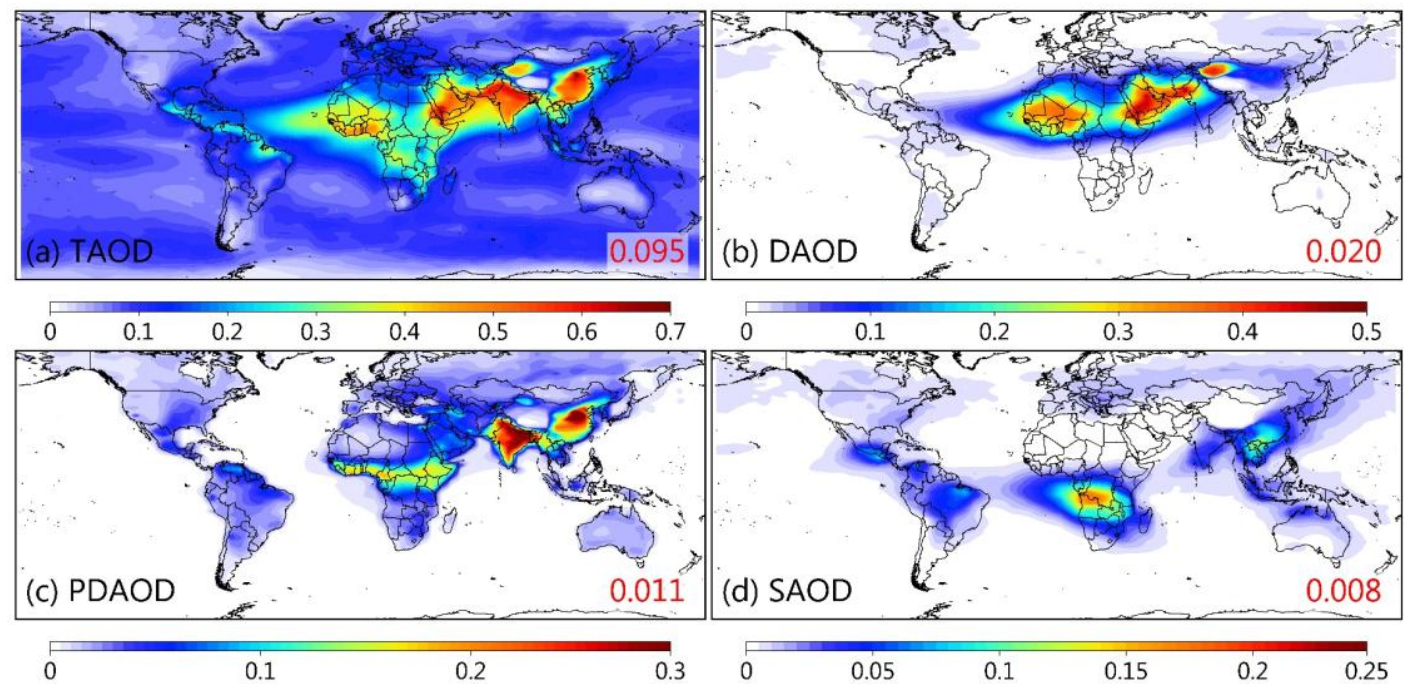

Figure S3. Spatial distributions of multi-year average AODs for (a) total aerosols, (b) dust, (c) PD, and (d) smoke. The number in the lower-right of each panel represents the global average. 


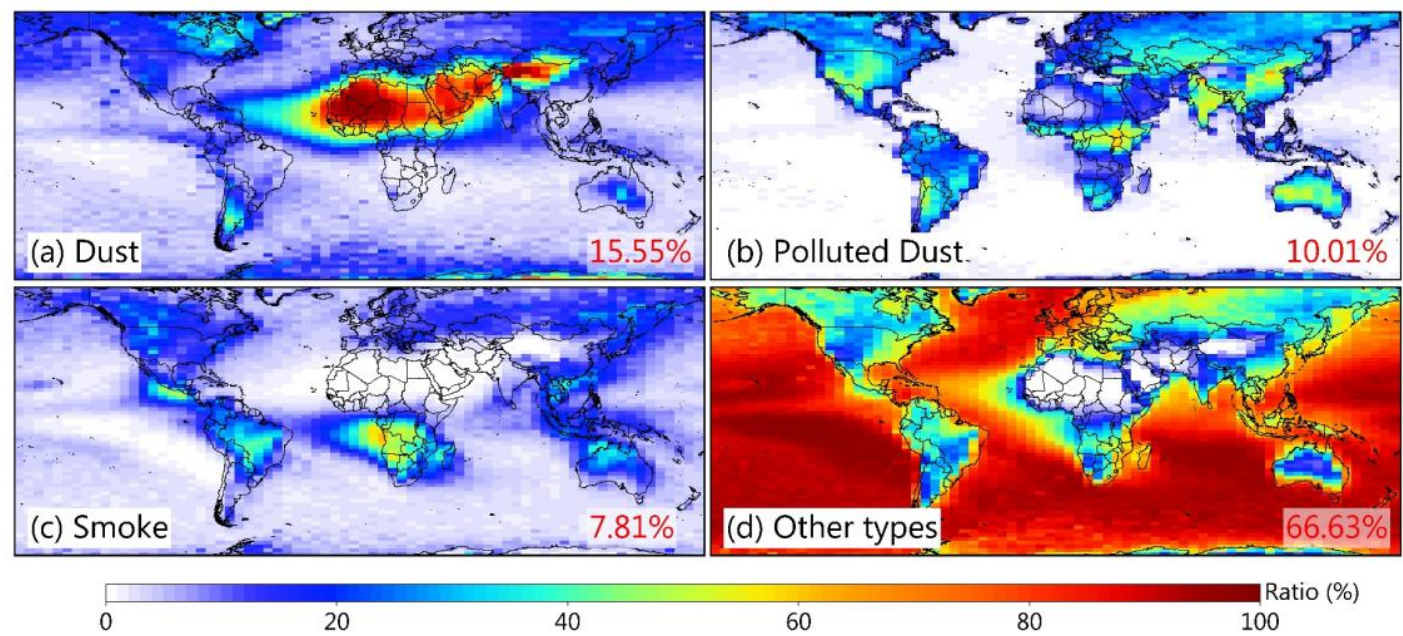

Figure S4. Spatial distributions of the multi-year average proportion of type-dependent AODs, including (a) dust, (b) PD, (c) smoke, and (d) other types, to total AOD. The number in the lower-right of each panel represents the global average. 
(a) TAOD

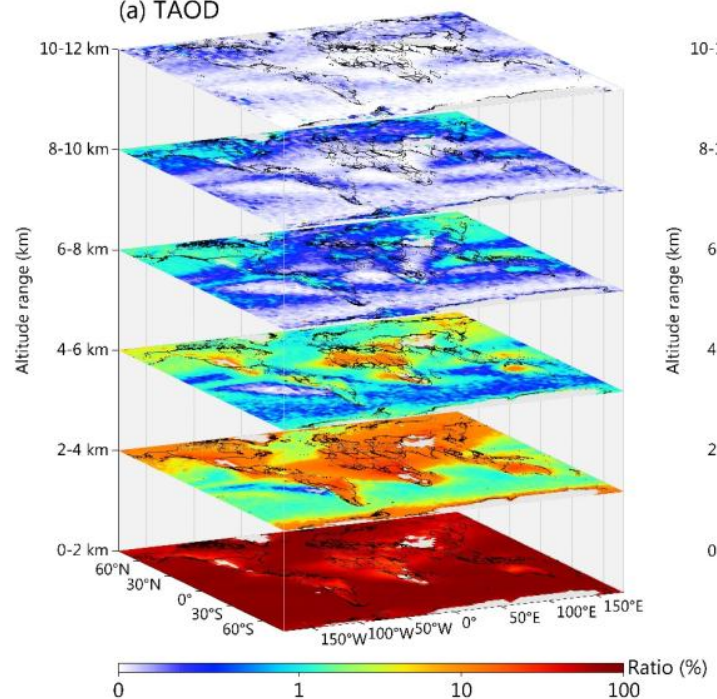

(c) PDAOD

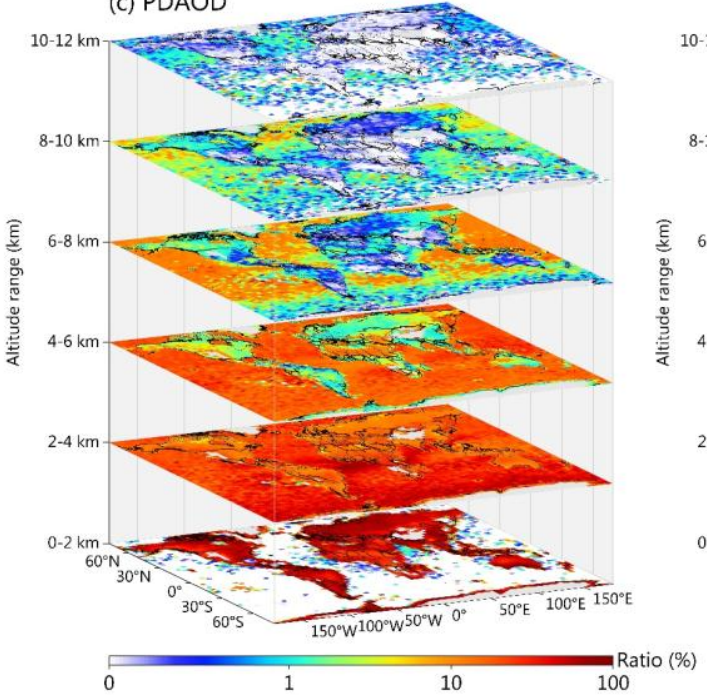

(b) $D A O D$

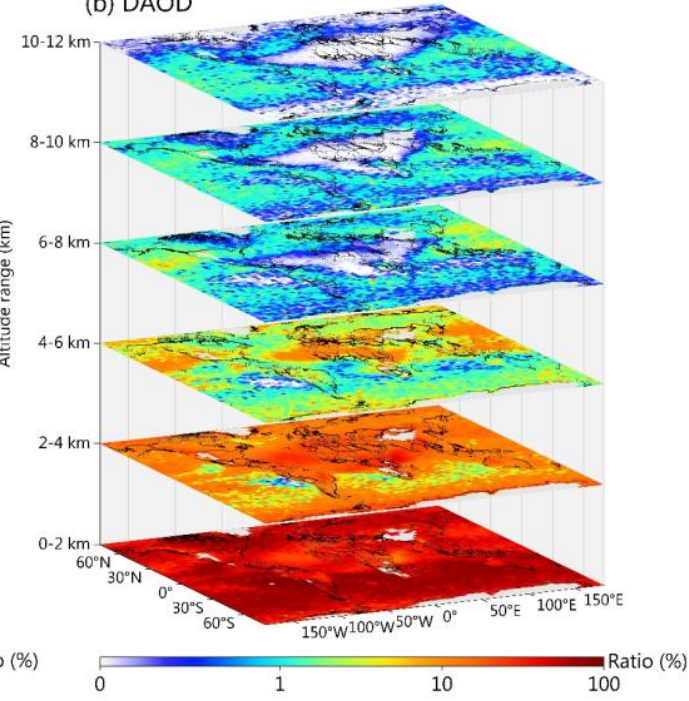

(d) SAOD

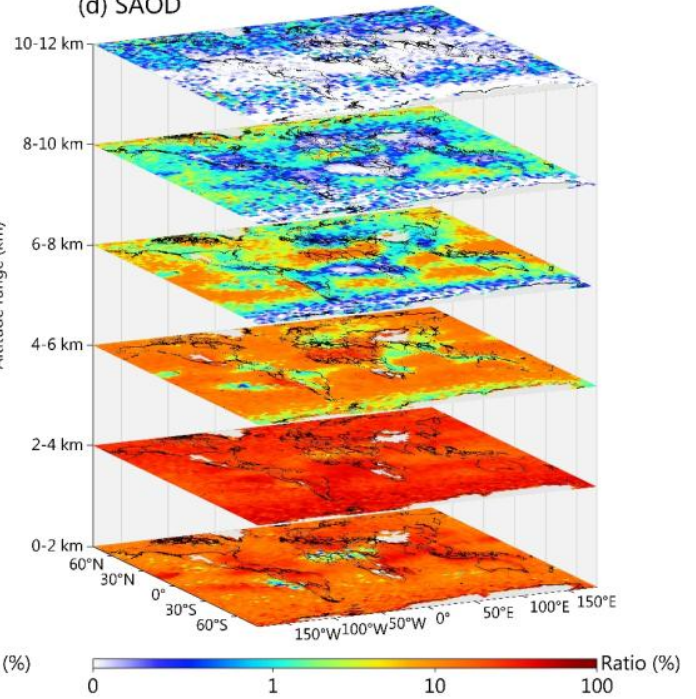

Figure S5. Spatial distributions of multi-year average proportions of type-dependent layer-specific (i.e., integrated at 2-km intervals

60 from the surface to $12 \mathrm{~km}$ ) AODs, including (a) total aerosols, (b) dust, (c) PD, and (d) smoke, to total type-dependent AODs. 

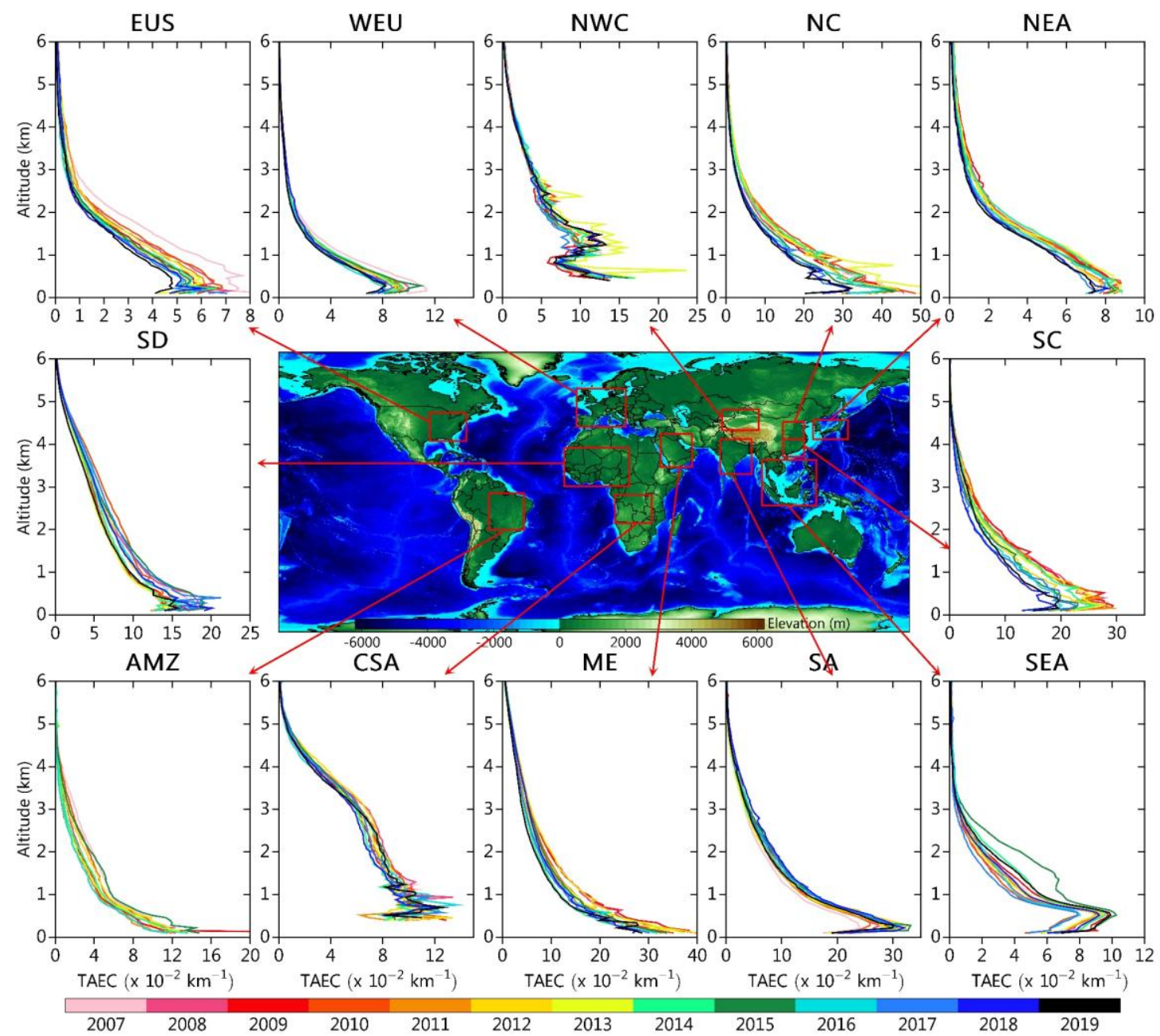

$2015 \quad 2016 \quad 2017$

2018

2019

Figure S6. Interannual variations in regional-average vertical profiles of the total AEC over the 12 ROIs. 

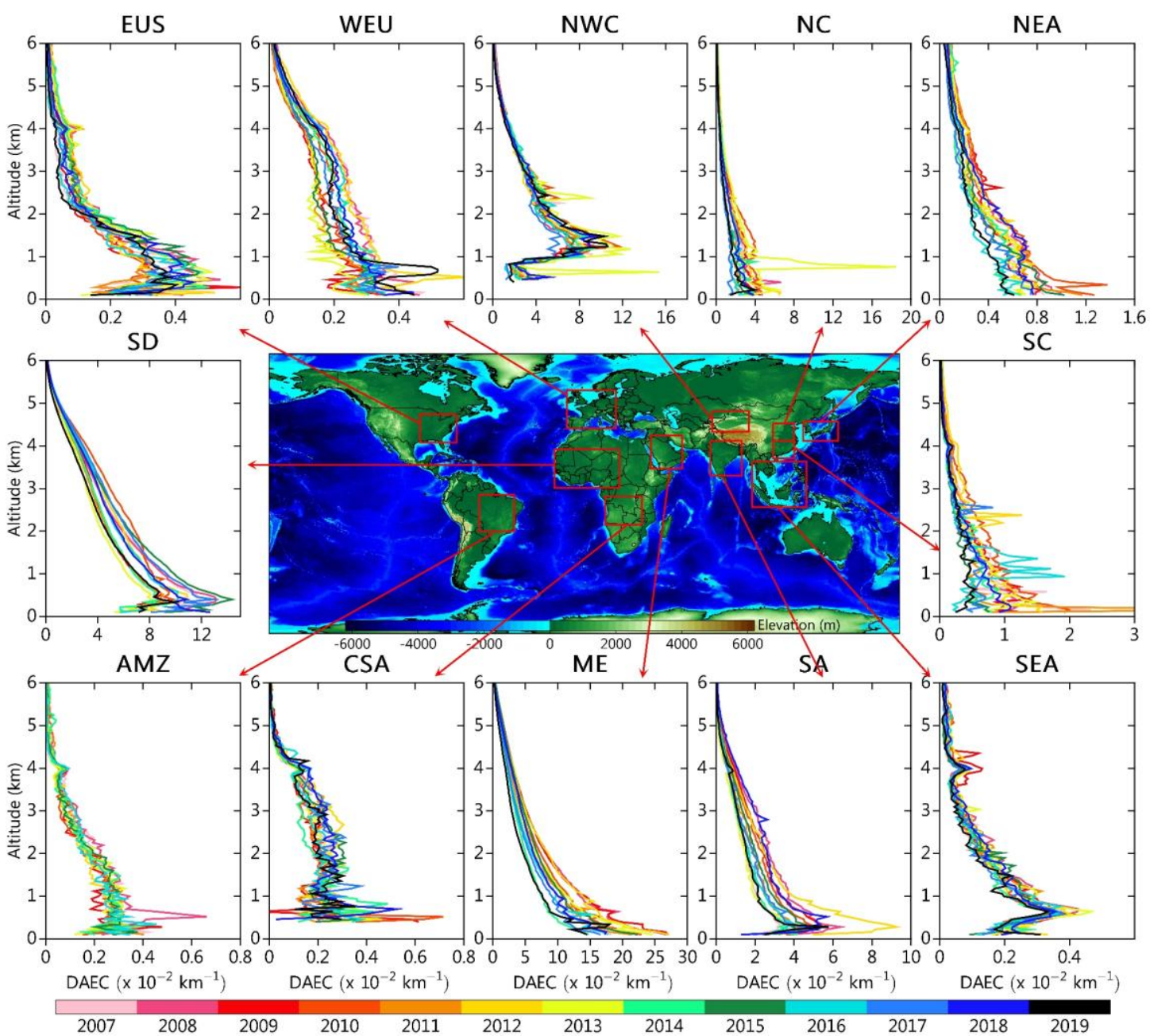

65 Figure S7. As in Figure S6 but for AEC due to dust. 

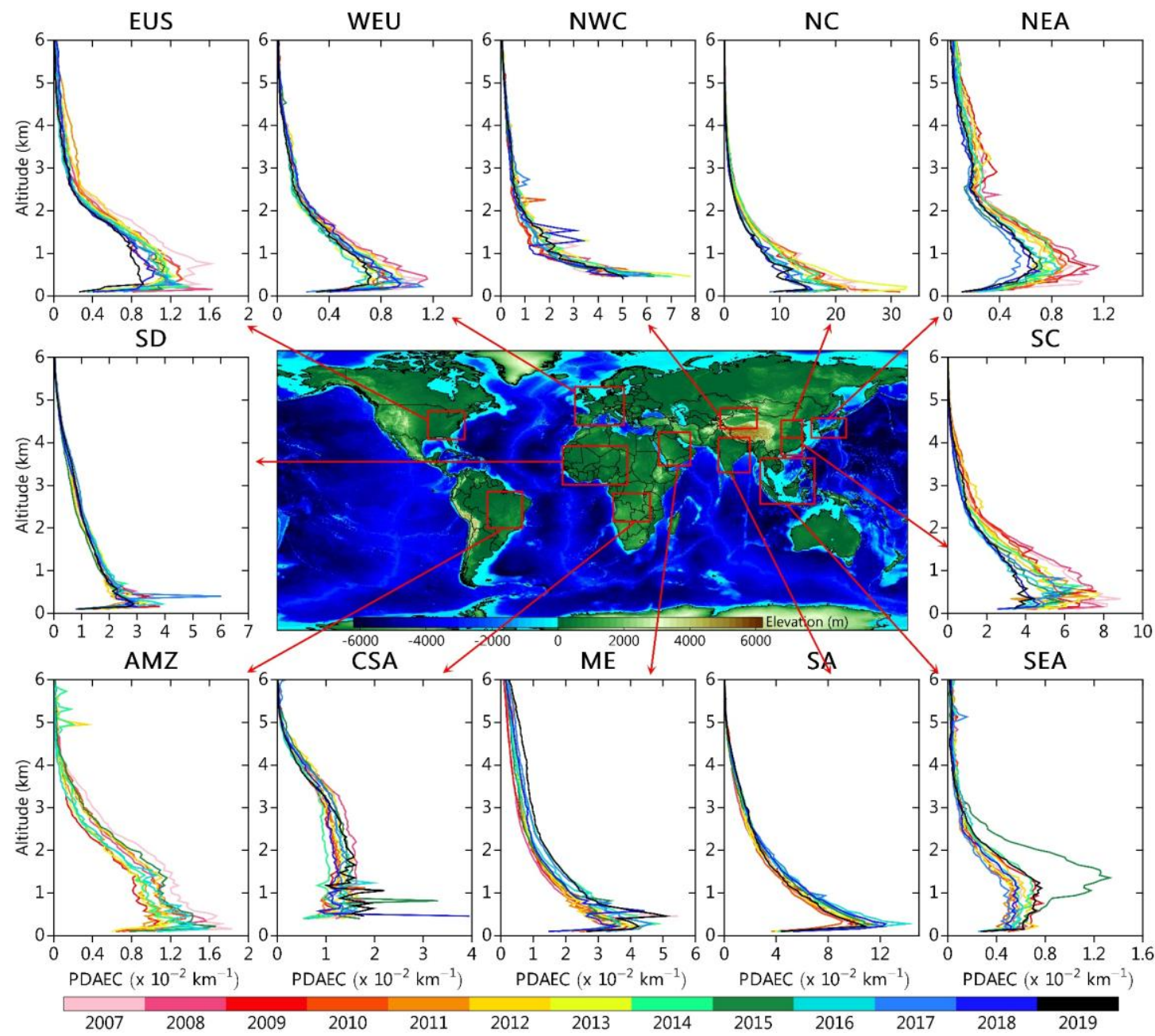

Figure S8. As in Figure S6 but for AEC due to PD. 

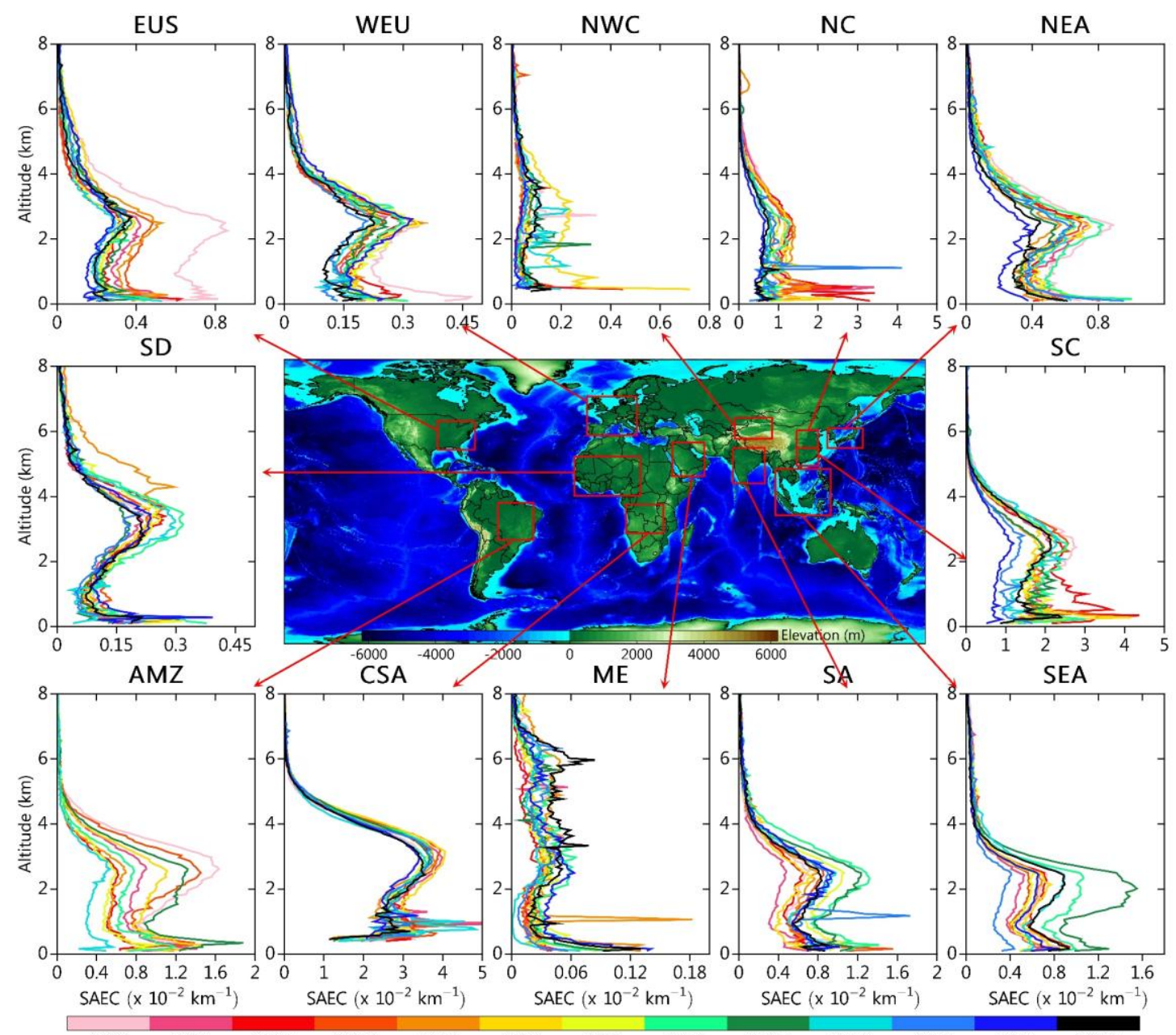

$2007 \quad 2008 \quad 2009$
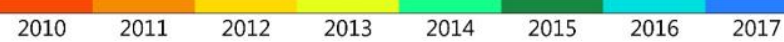

$2018 \quad 2019$

Figure S9. As in Figure S6 but for AEC due to smoke. 

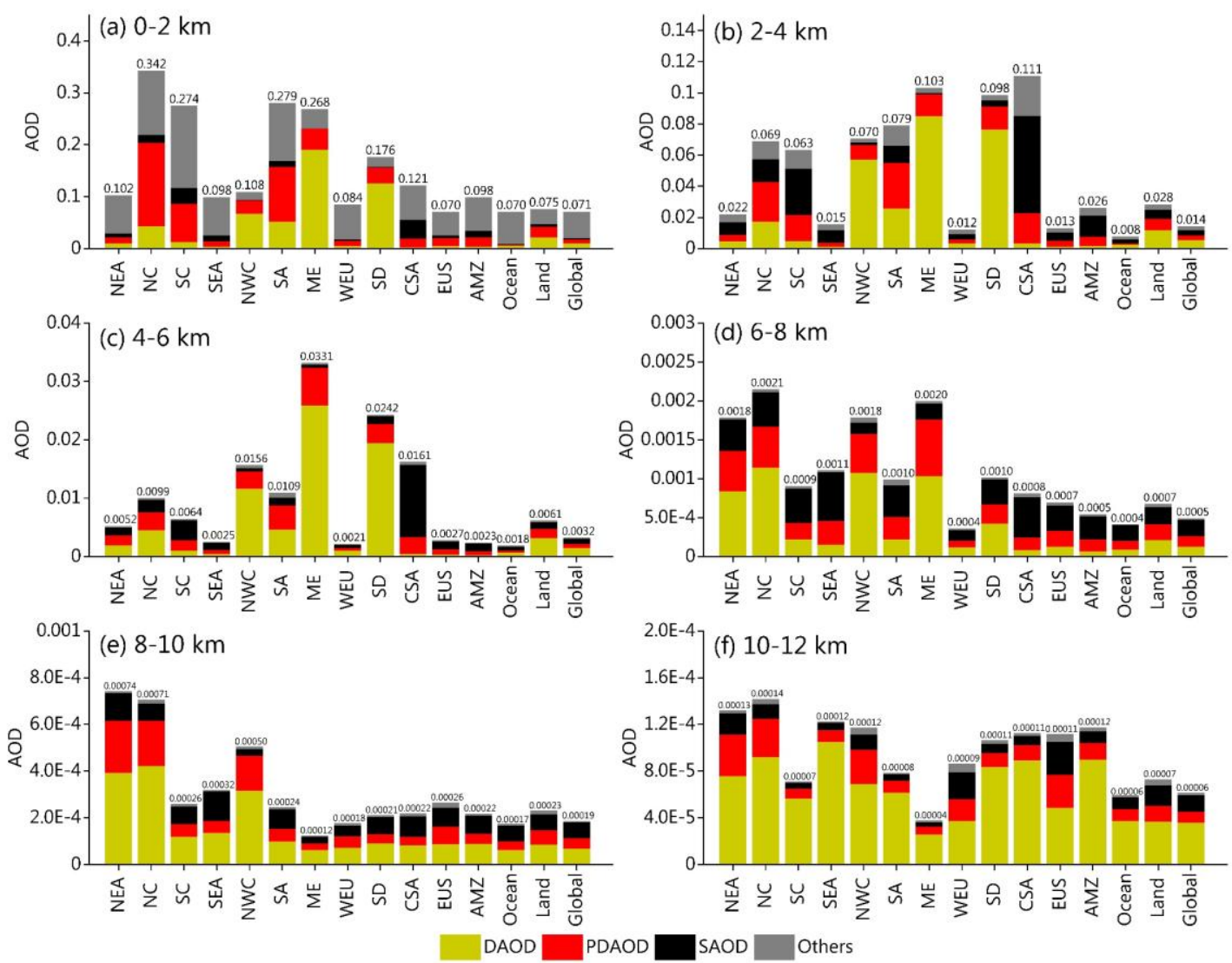

75

Figure S10. Multi-year regional-average layer-specific type-dependent AODs integrated at (a) 0-2 km, (b) 2-4 km, (c) 4-6 km, (d) 6-8 km, (e) 8-10 km, and (f) $10-12 \mathrm{~km}$. 


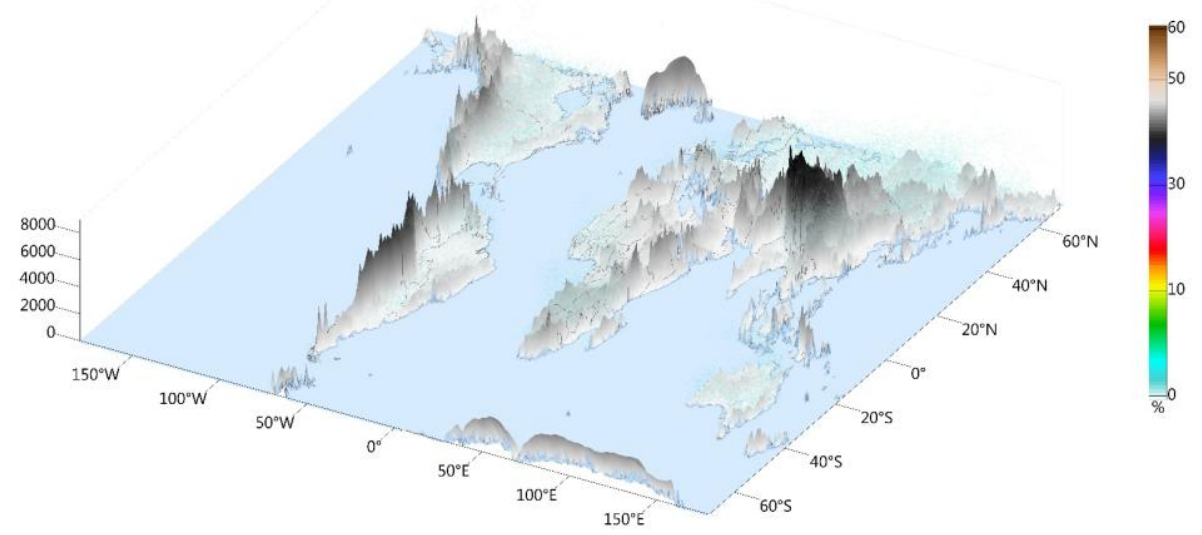

Figure S11. 3D particle map of the annual FoO for the clean continental (CC) averaged over 13 years (2007-2019). 
(a) NEA

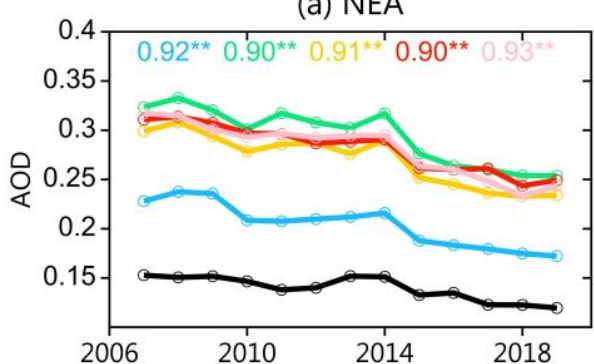

(d) SEA

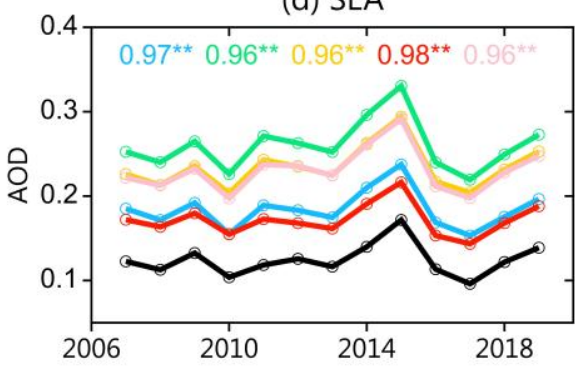

(g) $\mathrm{ME}$

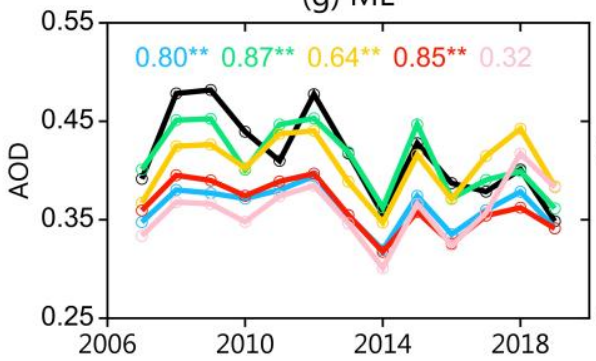

(j) CSA

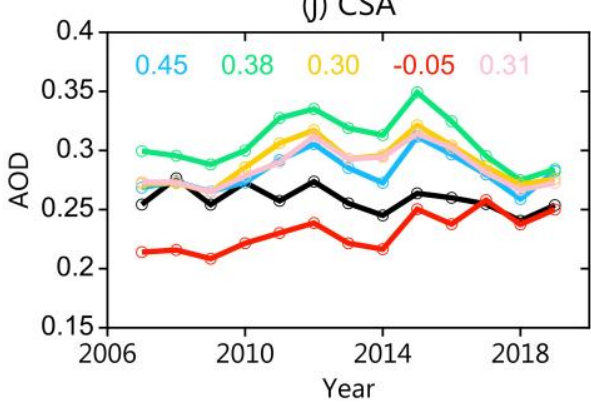

(b) NC

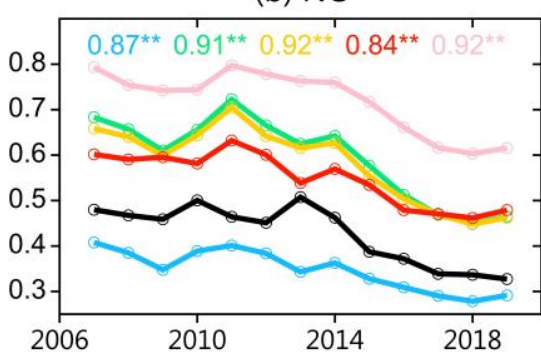

(e) NWC

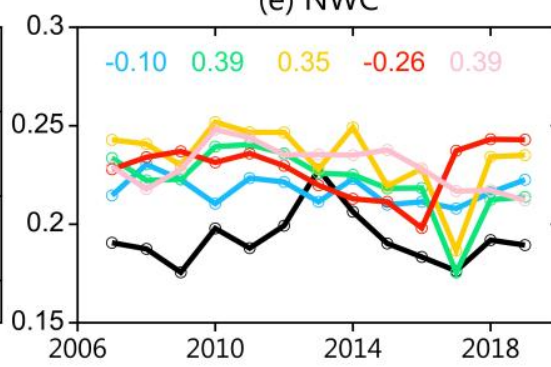

(h) WEU

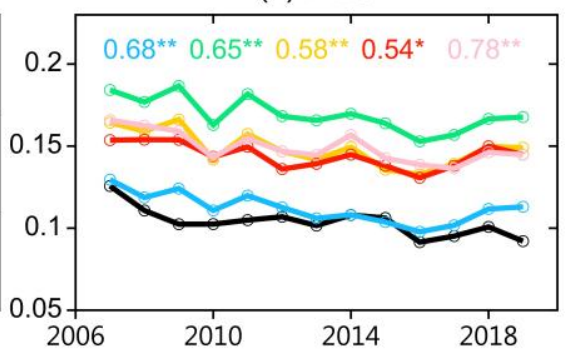

(k) EUS

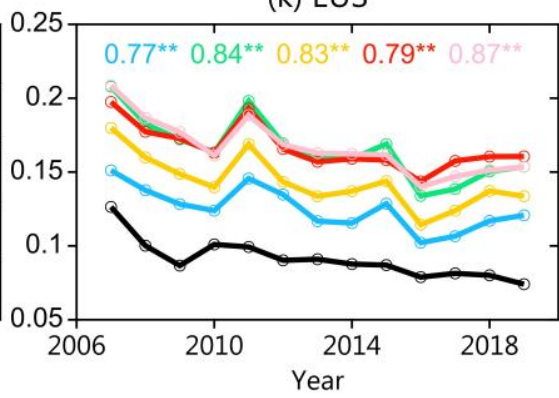

(c) SC

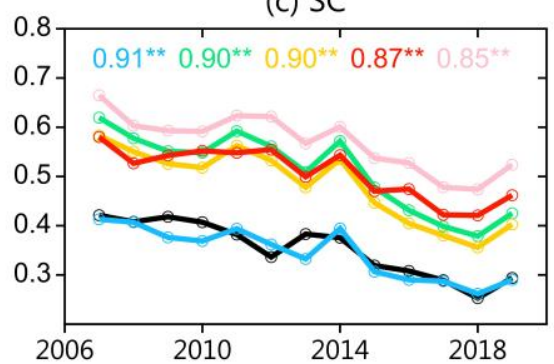

(f) $\mathrm{SA}$

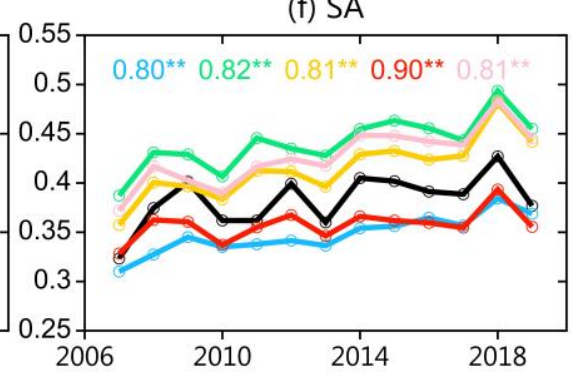

(i) $\mathrm{SD}$

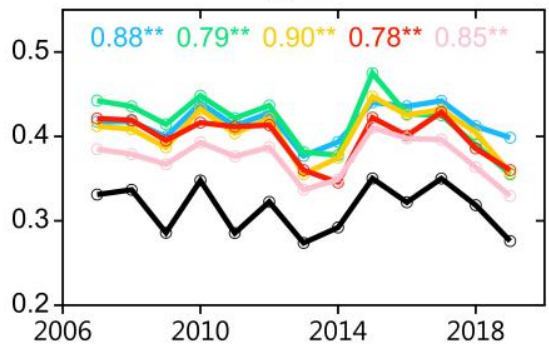

(I) $\mathrm{AMZ}$

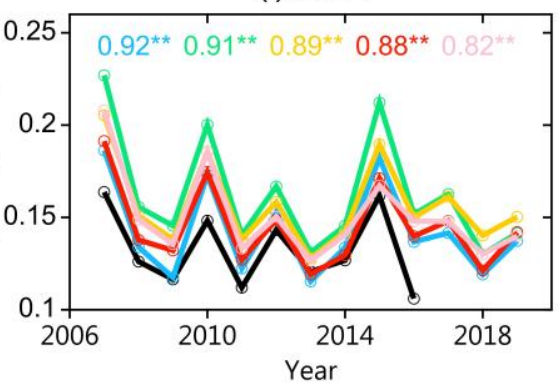

$-\mathrm{CALIPSO}=\mathrm{MISR}=\mathrm{MODIS} /$ Terra $-\mathrm{MODIS} /$ Aqua $=\mathrm{MERRA}-2-\mathrm{CAMS}$

Figure S12. Interannual variations in regional AOD averaged over the 12 regions of interest (ROIs). Note that the colored numbers inserted at the top of each panel represent the correlation coefficients $(R)$ between CALIPSO and the other five datasets. Numbers labeled with $*$ and ** represent $R$ values above the $90 \%$ and $95 \%$ significance levels from two-tailed Student's t-tests, respectively. 
(a) PPT

(b) VSM

(c) WS

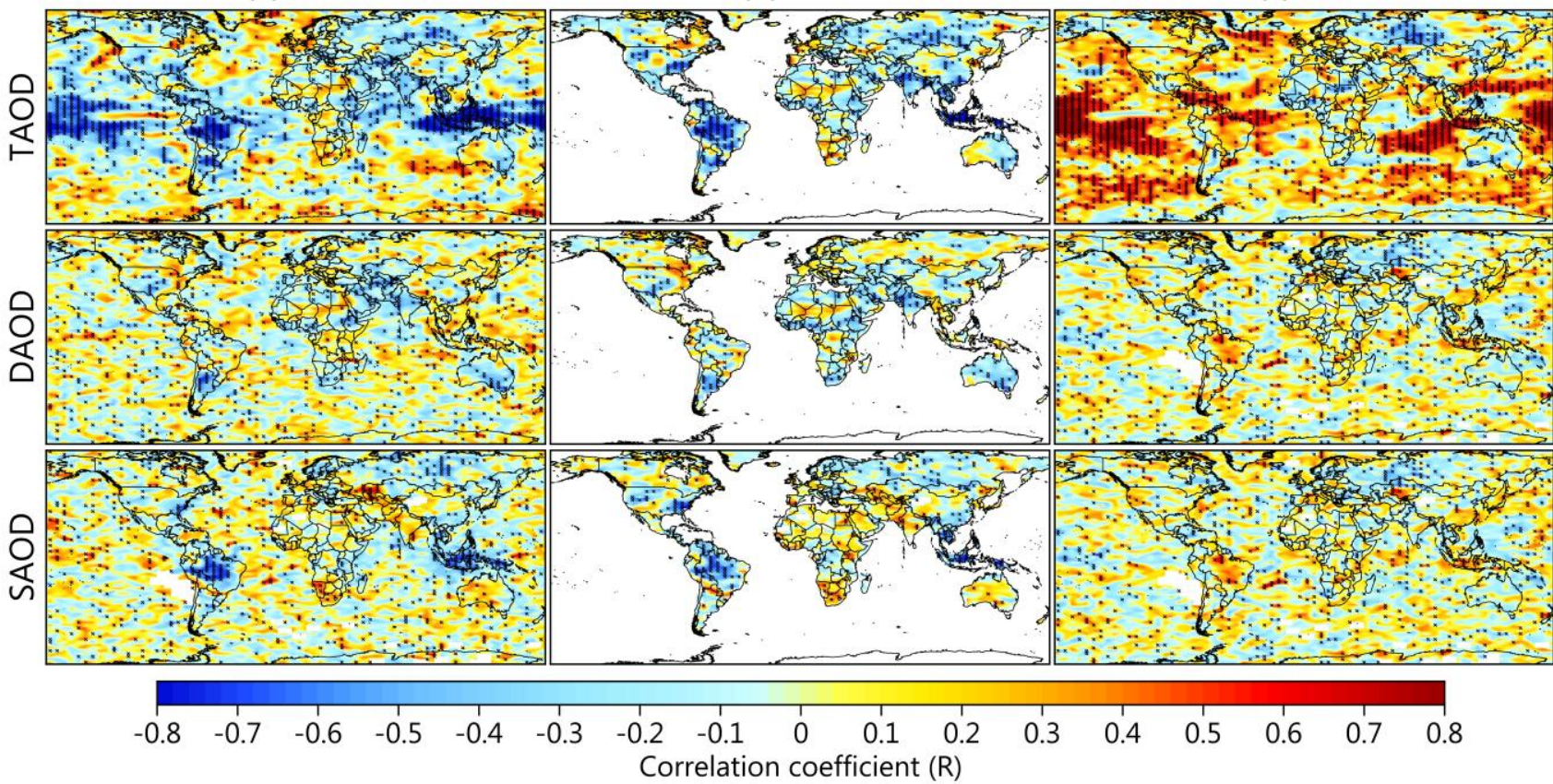

Figure S13. Spatial distributions of the correlation coefficients $(R)$ for TAOD, DAOD, and SAOD in the planetary boundary layer versus (a) precipitation (PPT), (b) volumetric soil moisture (VSM), and (c) wind speed at $10 \mathrm{~m}$ (WS) for 2007-2019. Note that the

95 grids with $\boldsymbol{R}$ at a $90 \%$ significance level from the two-tailed Student's t-test are marked by black " $x$ " symbols. 
(a) PPT

(b) VSM

(c) WS

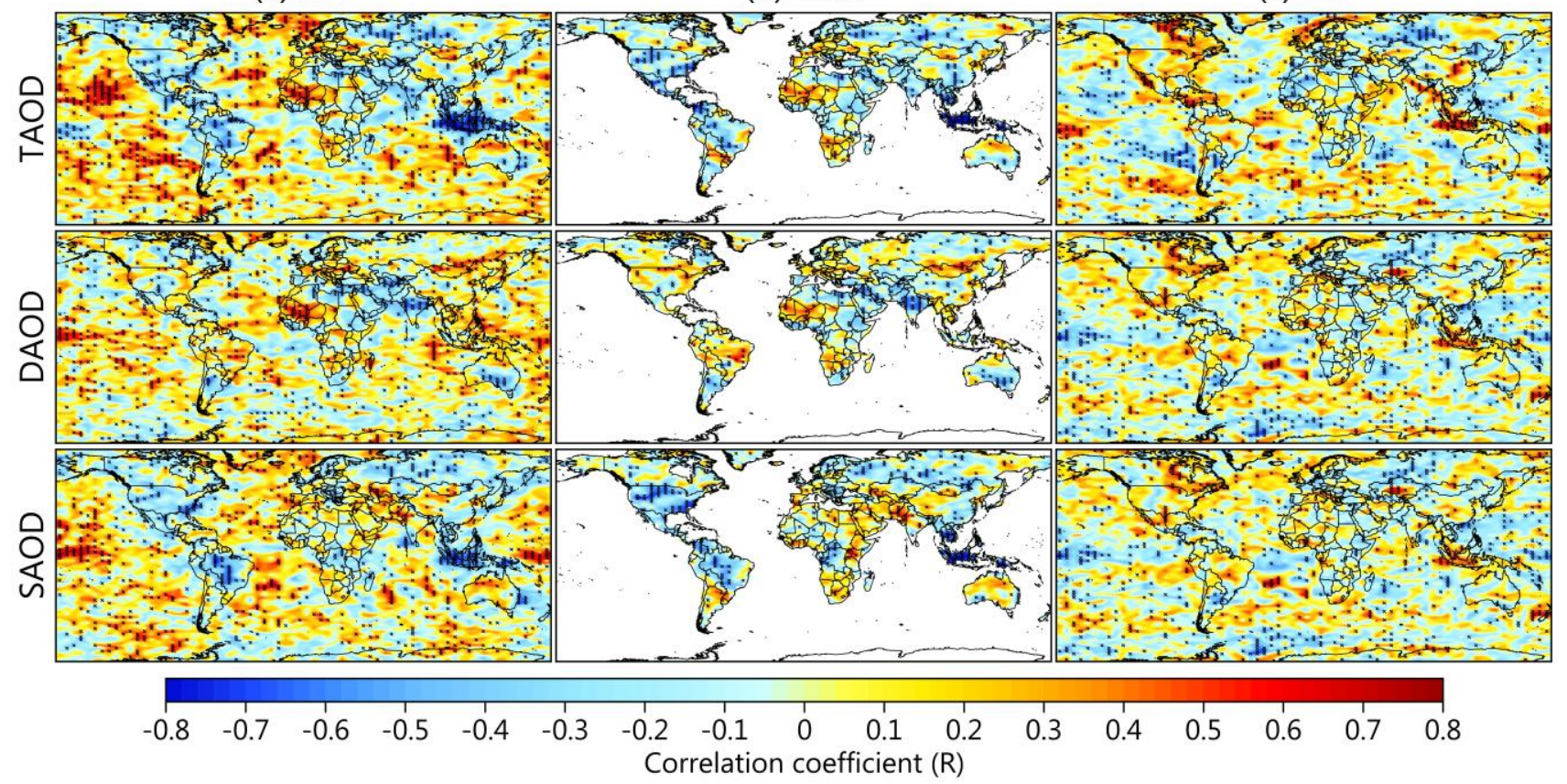

Figure S14. Spatial distributions of the correlation coefficients $(R)$ for TAOD, DAOD, and SAOD in the free troposphere versus (a)

100 PPT, (b) VSM, and (c) WS for 2007-2019. Note that the grids with $R$ at a 90\% significance level from the two-tailed Student's t-test are marked by black " $x$ " symbols. 